\title{
Self-Rated Health and Sick Leave among Nurses and Physicians: The Role of Regret and Coping Strategies in Difficult Care-Related Situations
}

\author{
Stéphane Cullati $1^{1,2,3,4+}$, Boris Cheval1,2,5,6*t, Ralph E. Schmidt ${ }^{5}$, Thomas Agoritsas ${ }^{7,8,9}$, \\ Pierre Chopard ${ }^{1,2}$ and Delphine S. Courvoisier ${ }^{1,2}$ \\ ${ }^{1}$ Quality of Care Service, University Hospitals of Geneva, Geneva, Switzerland, ${ }^{2}$ Department of General Internal Medicine, \\ Rehabilitation and Geriatrics, University of Geneva, Geneva, Switzerland, ${ }^{3}$ Swiss NCCR "LIVES: Overcoming Vulnerability: \\ Life Course Perspectives", University of Geneva, Geneva, Switzerland, " Institute of Sociological Research, University of \\ Geneva, Geneva, Switzerland, ${ }^{5}$ Department of Psychology, University of Geneva, Geneva, Switzerland, ${ }^{6}$ Methodology and \\ Data Analysis Laboratory, University of Geneva, Geneva, Switzerland, ${ }^{7}$ Division of General Internal Medicine, University \\ Hospitals of Geneva, Geneva, Switzerland, ${ }^{8}$ Division of Clinical Epidemiology, University Hospitals of Geneva, Geneva, \\ Switzerland, ${ }^{9}$ Department of Clinical Epidemiology and Biostatistics, McMaster University, Faculty of Health Sciences, \\ Hamilton, ON, Canada
}

OPEN ACCESS

Edited by:

Gianluca Castelnuovo Università Cattolica del Sacro Cuore,

Italy

Reviewed by: Jimmy Thomas Efird, East Carolina University, USA Volker Max Perlitz,

Simplana GmbH, Germany

${ }^{*}$ Correspondence:

Boris Cheval

boris.cheval@unige.ch

${ }^{\dagger}$ These authors have contributed equally to this work.

Specialty section:

This article was submitted to Psychology for Clinical Settings, a section of the journal Frontiers in Psychology

Received: 15 September 2016 Accepted: 04 April 2017

Published: 20 April 2017

Citation: Cullati S, Cheval B, Schmidt RE,

Agoritsas T, Chopard P and Courvoisier DS (2017) Self-Rated Health and Sick Leave among Nurses and Physicians: The Role of Regret and Coping Strategies in Difficult

Care-Related Situations.

Front. Psychol. 8:623. doi: 10.3389/fpsyg.2017.00623
Moral distress - such as feeling strong regret over difficult patient situations - is common among nurses and physicians. Regret intensity, as well as the coping strategies used to manage regrets, may also influence the health and sickness absence of healthcare professionals. The objective of this study was to determine if the experience of regret related to difficult care-related situations is associated with poor health and sick leave and if coping strategies mediate these associations. Two cross-sectional surveys were conducted in Switzerland (Geneva, 2011 and Zurich, 2014). Outcomes were self-rated health $(\mathrm{SRH})$ and sick leave in the last 6 months. We examined the associations of regret intensity with the most important care-related regret, number of recent care-related regrets, and coping strategies, using regressions models. Among 775 respondents, most reported very good $\mathrm{SRH}$ and $9.7 \%$ indicated absence from work during four working days or more. Intensity of the most important regret was associated with poor SRH among nurses and physicians, and with higher sick leave among nurses. Maladaptive emotion-focused strategies were associated with poor $\mathrm{SRH}$ among nurses, whereas adaptive emotion-focused strategies were positively associated with higher $\mathrm{SRH}$ and lower sick leave among physicians. Because care-related regret is an integral part of clinical practice in acute care hospitals, helping physicians and, especially, nurses to learn how to deal with negative events may yield beneficial consequences at the individual, patient care, and institutional level.

Keywords: self-rated health, sick leave, moral distress, healthcare-related regrets, nurses, physicians

\section{INTRODUCTION}

Providing safe and good quality healthcare to patients in acute care settings requires healthy healthcare professionals (such as physicians and nurses) (Rowe and Kidd, 2009; West et al., 2009). Yet, many studies have documented that healthcare professionals' own health is often far from optimal. Compared to the general population, healthcare professionals more frequently report 
poor self-rated health (SRH) (Knecht et al., 2010; Malinauskiene et al., 2011), sleeping problems or poor sleep quality (Aasa et al., 2005; Hsieh et al., 2011; Bjorvatn et al., 2012; Ghalichi et al., 2013), and suffer more often from depression (Embriaco et al., 2012) or burn out (Embriaco et al., 2007; Arigoni et al., 2010; Merlani et al., 2011). The economic burden of these healthrelated problems is high for institutions (Schultz et al., 2009; Letvak et al., 2012).

Similarly, moral distress is also common among healthcare professionals working in acute care settings (Pauly et al., 2009; Sirriyeh et al., 2010; Huffman and Rittenmeyer, 2012; Burston and Tuckett, 2013; Oh and Gastmans, 2015). Moral distress can be related to the healthcare professionals' negative judgment about the quality of care he/she provided to the patients, such as inappropriate care (Piers et al., 2011), loss of control (Shapiro et al., 2011) or stress of conscience (Glasberg et al., 2008), or to healthcare professionals' involvement in medical errors (Sirriyeh et al., 2010). One emotional facet of moral distress is the experience of regret (Zeelenberg and Pieters, 2007). Healthcare professionals may regret the care that they provided when they feel that it was inconsistent with their personal beliefs or clinical knowledge (Courvoisier et al., 2011, 2013b). The experience of care-related regret is frequent (Courvoisier et al., 2013a), in part because working in acute care hospitals constrains the way healthcare professionals make clinical decisions and attend to patients' care. The hospital setting entails high workload (Hugonnet et al., 2007; Weissman et al., 2007), shift work, information overload (Rössler, 2012), and the daily confrontation with numerous complex and uncertain clinical situations (Thompson and Dowding, 2001; Nevalainen et al., 2013). Experiencing regrets, may be associated with poor health conditions among healthcare professionals (Schmidt et al., 2015).

Conceptually, three aspects of care-related regret may influence health: the intensity of the most important regret, the accumulation of small regrets experienced throughout the daily working time, and the strategies used to cope with daily regrets (Figure 1) (Courvoisier et al., 2013b). The strategies can be further categorized into three main types: problemfocused strategies (e.g., talking to the patient), emotion-focused adaptive strategies (e.g., accepting one's own limitations or the inherent limitations of medicine), and emotion-focused maladaptive strategies (e.g., ruminating the events and possible implications). A systematic review showed that adaptive strategies are frequent when healthcare professionals are facing patient adverse events (Seys et al., 2013). Although adaptive strategies may reduce the burden of regret intensity and regret accumulation on health (DeSteno et al., 2013), no study has yet examined specific mechanisms underlying the associations.

The objectives of the present study conducted among hospitalbased nurses and physicians were therefore to assess whether their health conditions (SRH and self-reported absenteeism) are associated with (1) care-related regrets (intensity of most important regret, accumulation of regrets) and regret coping strategies; and (2) to test whether coping strategies mediated the associations between care-related regrets and health conditions.

\section{MATERIALS AND METHODS}

\section{Study Design}

A first survey was conducted in 2011 at the University Hospitals of Geneva, a 1800-beds Swiss public hospital network. Mail questionnaires were sent to 825 nurses and 825 physicians with up to three reminders. A second survey was conducted in 2014 at the Stadtspital Triemli, Zurich (500-beds hospital) and at the Bezirksspital Affoltern am Albis (100-beds hospital). In this second survey, participants were informed that a small incentive for each completed questionnaire was donated to the Children's Charity "Theodora" ("Giggle doctors," Aargau, Switzerland). Physicians or nurses were excluded from these studies if they did not practice in the past 5 years, were retired, or reported the absence of any regrets. The World Medical Association's Declaration of Helsinki was followed in the conduct of the study. The Research Ethics Committee of the University Hospitals of Geneva and the Ethics Committee Zurich indicated that both surveys were exempted from formal research ethics approval.

\section{Outcomes}

SRH was measured by the first question of the Short Form (36) Health Survey. Following the stem "In general, do you think your health is..." participants were asked to rate their health as bad (1), fair (2), good (3.7), very good (4.5), or excellent (5). This coding scheme $(1,2,3.7,4.5$, and 5$)$ was used to better capture the underlying health construct, since the magnitudes between the response options are not evenly distributed as an interval variable (Perneger et al., 2013). SRH is regularly used in health surveys because it measures physical, mental, and social dimensions of health (Singh-Manoux et al., 2006; Perruccio et al., 2012), and predicts several health outcomes, such as sick leave (Halford et al., 2012) and mortality (Aichele et al., 2016).

Sick leave was measured with a question asking respondents the number of workdays they missed in the last 6 months, excluding leaves related to pregnancy and maternity. This variable was dichotomized at the 75th percentile for each profession, that is 0 day versus 1 day or more for physicians, and $0-3$ days versus 4 or more days for nurses.

\section{Independent Variables}

The intensity of the most important care-related regret was assessed with the 10-item regret intensity scale (RIS-10) (Courvoisier et al., 2013a). The regret must be related to providing healthcare to a patient, and experienced less than 5 years ago. Items are assessed with a five-point Likert scale ranging from "not at all" to "absolutely." The RIS-10 possesses good psychometric properties, with an internal consistency of 0.87 (Cronbach's alpha) and a test-retest reliability of 0.70 . In addition to the RIS-10, one question probed whether the respondent felt that the event eliciting their most important regret was related to an error ("According to you, did this event imply an error on your part" answered yes or no).

Care-related regret coping was assessed with the 15-item regret coping scale (RCS-HCP) (Courvoisier et al., 2014), developed to assess daily coping strategies used by healthcare professionals 


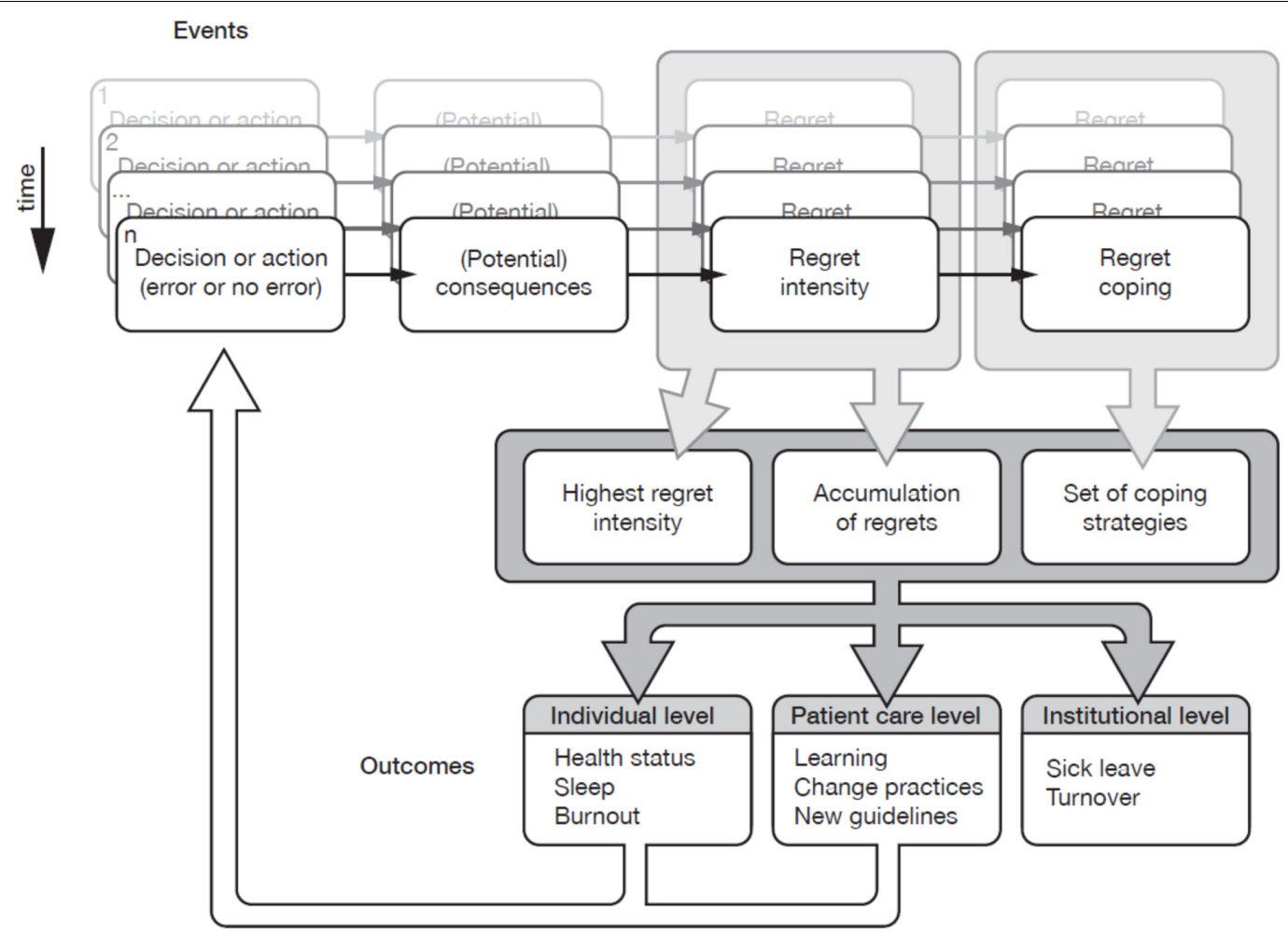

FIGURE 1 | Theoretical framework of experiencing regret in clinical practice and its implications. Lancet (Courvoisier et al., 2013b).

to deal with regrets they feel when providing care to patient. Using a four-point Likert scale ranging from 1 ("never or almost never") to 4 ("always or almost always"), RCS-HCP measures how frequently the respondent uses the three types of regret regulation strategies: problem-focused strategies, emotion-focused adaptive strategies, and emotion-focused maladaptive strategies. The three subscales of RCS-HCP have good psychometric properties, with internal consistencies close to 0.90 (Cronbach's alpha) and testretest agreement ranging from 0.78 to 0.82 (Courvoisier et al., 2014).

Recent care-related regrets were assessed using two questions: "Within these last 30 working days, how many situations with patients have you regretted?" and "What is the mean intensity you would give to these situations within the last 30 days?," on a visual analog scale from 0 to 10 . If the respondent reported no regret in the last 30 days, the mean intensity was imputed as 0 .

Professional and socio-demographic items were assessed with questions including gender, age, profession (physician or nurse), supervising role (yes, no), years of clinical experience, and percentage of clinical activity $(0-50,51-80,>80 \%)$.

\section{Analysis}

The associations of the three care-related variables (i.e., current intensity of the most important regret in the last 5 years, whether the most important regret was an error, number of recent regrets and regret coping) with SRH were examined using linear regression for the SRH score and logistic regression for sick leave. For each outcome, we ran two types of multivariable models. In the first type, we adjusted the analysis of each variable related to regret with the socio-professional variables: gender, years of experience, professional status, percentage of clinical activity, and linguistic region of the hospital. Age was not included because it was too strongly related with years of experience. In the second type of multivariable models, all variables pertaining to care-related regrets and all socioprofessional variables were included. All analyses were conducted separately for nurses and physicians. Mediation analyses were performed using Sobel tests with bootstrap confidence intervals. Specifically, the Sobel test compares the coefficient of each regret variable in a model adjusted for socio-professional variables (the corresponding coefficient is called c) to the coefficient of the same regret variable in the model adjusted for socio-professional variables and a regret coping strategy (the corresponding coefficient is called $c^{\prime}$ ). Mediation analyses tested each dimension of coping separately and the three dimensions together. All analyses were conducted with R (version 3.2.4, Vienna, Austria).

We further conducted two sensitivity analyses. First, we ran the same analyses on all healthcare professionals, without stratifying on profession (nurses and physicians together). Second, we examined others ways to model SRH than as a continuous variable with evenly spaced ratings values $(1,2,3.7$, 4.5, and 5) (Perneger et al., 2013), such as an interval scale or a dichotomized scale between very good or excellent versus less than very good. 


\section{RESULTS}

Overall, 775 participants returned the survey (22.5\% of the 3,452 eligible participants). Healthcare professionals had a mean age of 39.5 (SD: 9.1) years. The majority were women, nurses, and had a percentage of clinical activity between 80 and 100\% (Table 1). Mean number of years in clinical practice was 15 (median: 12, $S D$ : 10). Most healthcare professionals reported very good SRH status, physicians more than nurses $(p<0.001)$. Prolonged sick leaves ( $\geq 10$ days) were reported by $1.7 \%$ of physicians compared to $6.3 \%$ of nurses $(p<0.001)$.

\section{Care-Related Regret and Health Conditions among Nurses (Table 2)}

Adjusted analyses examining each regret variables separately (i.e., intensity of the most important regret, self-perceived error of the most important regret, number and intensity of recent regrets, regret coping) showed that higher intensity

TABLE 1 | Characteristics of healthcare professionals.

\begin{tabular}{|c|c|c|c|c|c|}
\hline \multirow{2}{*}{$\begin{array}{l}\text { Characteristics } \\
\text { Socio-professional: }\end{array}$} & \multirow[b]{2}{*}{ Categories } & \multirow{2}{*}{\multicolumn{2}{|c|}{$\begin{array}{l}\text { Nurses } \\
N=466\end{array}$}} & \multirow{2}{*}{\multicolumn{2}{|c|}{$\begin{array}{c}\text { Physicians } \\
\qquad N=309\end{array}$}} \\
\hline & & & & & \\
\hline \multirow[t]{2}{*}{ Gender } & Male & 64 & 13.9 & 138 & 44.7 \\
\hline & Female & 398 & 86.1 & 171 & 55.3 \\
\hline \multirow[t]{3}{*}{ Age } & $<30$ & 77 & 16.7 & 65 & 21.2 \\
\hline & $40-49$ & 133 & 28.8 & 69 & 22.6 \\
\hline & $>50$ & 95 & 20.6 & 28 & 9.2 \\
\hline \multirow[t]{2}{*}{ Professional status } & Nurse/resident & 395 & 86.2 & 141 & 45.8 \\
\hline & Head nurse/board certified & 63 & 13.8 & 167 & 54.2 \\
\hline \multirow[t]{2}{*}{ Percentage of clinical activity } & $0-50 \%$ & 35 & 7.5 & 10 & 3.3 \\
\hline & $51-80 \%$ & 174 & 37.5 & 40 & 13.1 \\
\hline & $6-10$ & 73 & 15.8 & 81 & 26.6 \\
\hline & $11-20$ & 148 & 32.0 & 74 & 24.3 \\
\hline & $>20$ & 185 & 40.0 & 42 & 13.8 \\
\hline \multirow[t]{2}{*}{ Hospital's linguistic region } & French & 249 & 53.4 & 220 & 71.2 \\
\hline & German & 217 & 46.6 & 89 & 28.8 \\
\hline \multicolumn{6}{|l|}{ Care-related regrets: } \\
\hline & Mean & SD & Mean & SD & \\
\hline $\begin{array}{l}\text { Current intensity of the most important regret experienced in the last } \\
5 \text { years (RIS-10) }\end{array}$ & 1.86 & 0.72 & 1.81 & 0.76 & \\
\hline Number of regrets (last month) & 2.36 & 15.4 & 1.00 & 1.5 & \\
\hline Mean intensity of regrets (last month) & 2.35 & 2.57 & 2.06 & 2.36 & \\
\hline \multirow[t]{5}{*}{ Self-rated health } & Bad & 1 & 0.2 & 0 & 0.0 \\
\hline & Fair & 29 & 6.3 & 14 & 4.5 \\
\hline & Good & 180 & 38.9 & 60 & 19.4 \\
\hline & Very good & 173 & 37.4 & 124 & 40.1 \\
\hline & Excellent & 80 & 17.3 & 111 & 35.9 \\
\hline \multirow[t]{5}{*}{ Sick leave } & 0 days & 301 & 65.3 & 239 & 77.4 \\
\hline & $1-3$ days & 101 & 21.9 & 56 & 18.1 \\
\hline & $4-5$ days & 14 & 3.0 & 4 & 1.3 \\
\hline & $6-10$ days & 16 & 3.5 & 5 & 1.6 \\
\hline & $\geq 10$ days & 29 & 6.3 & 5 & 1.6 \\
\hline
\end{tabular}


of the most important regret was associated with poor SRH and sick leave, and that more frequent use of maladaptive coping strategies was associated with poor SRH. Perceiving the most important regret as an error and recent regrets experienced in the previous 30 working days (number of regrets and mean intensity) were not associated with health conditions.

In adjusted models including all regret variables, intensity of the most important regret and more frequent use of maladaptive coping strategies remained associated with poor health conditions. Analysis of the mediation effects of regret coping strategies revealed that maladaptive emotion-focused coping partly mediated the effect of intensity of the most important regret (c-c' estimate: -0.05 , bootstrap $95 \% \mathrm{CI}$ : $[-0.10 ;-0.01])$ on SRH only, while problem-focused and adaptive strategies had no mediation effect (Supplementary Material).

\section{Care-Related Regret and Health Conditions among Physicians (Table 3)}

Adjusted analyses examining regret variables separately showed that higher level in intensity of the most important regret and of recent regrets were associated with poor SRH. More frequent use of adaptive coping strategies was associated with good SRH and with lower probability of sick leave, while more frequent use of maladaptive strategies was associated with poor SHR. As in the sample of nurses, perceiving the most important regret as an error was not associated with health conditions.

In adjusted models including all regret variables, only more frequent use of adaptive coping strategies remained associated with health conditions, while factors like intensity of the most important regret and of recent regrets were no longer associated with SRH. Analysis of the mediation effects of regret coping strategies revealed that more frequent use of adaptive emotionfocused strategies had an indirect, protective, effect in three associations: between recent regrets and sick leave ( $c-c^{\prime}$ estimate: -0.58 , bootstrap 95\%CI: $[-2.82 ;-0.08])$ and between the most important regret and SRH $(0.08,[0.02 ; 0.18])$ and sick leave $(0.08$, $[0.01 ; 0.17])$ (Supplementary Material).

\section{Sensitivity Analysis}

Analyses without stratifying on profession (nurses and physicians together) yielded similar results. When SRH was dichotomized, the only significant predictors of SRH were adaptive strategies for physicians (OR $=0.64,95 \% \mathrm{CI}$ : [0.46; $0.86]$ ) and maladaptive strategies for nurses ( $\mathrm{OR}=1.42$, 95\%CI: [1.10; 1.85]). By contrast, when SRH was treated as an interval scale results were similar to the previous ones.

TABLE 2 | Association of care-related regret with health conditions among nurses.

\begin{tabular}{|c|c|c|c|c|c|c|}
\hline \multirow[b]{2}{*}{ Self-rated health } & \multicolumn{3}{|c|}{ Adjusted analyses, regret variables not included* } & \multicolumn{3}{|c|}{ Adjusted analyses, all regret variables included* } \\
\hline & Slope & $p$ & $95 \% \mathrm{Cl}$ & Slope & $p$ & $95 \% \mathrm{Cl}$ \\
\hline \multicolumn{7}{|c|}{ Most important care-related regret in the last 5 years } \\
\hline Current intensity (RIS-10) & -0.19 & $<0.001$ & $-0.29 ;-0.09$ & -0.15 & 0.04 & $-0.25 ;-0.02$ \\
\hline Self-perceived error & -0.12 & 0.26 & $-0.34 ; 0.09$ & 0.03 & 0.84 & $-0.23 ; 0.33$ \\
\hline \multicolumn{7}{|c|}{ Recent care-related regrets (last 30 working days) } \\
\hline Number of regrets & -0.01 & 0.74 & $-0.08 ; 0.06$ & -0.03 & 0.48 & $-0.09 ; 0.05$ \\
\hline Mean intensity & -0.04 & 0.44 & $-0.15 ; 0.06$ & -0.00 & 0.99 & $-0.12 ; 0.10$ \\
\hline \multicolumn{7}{|c|}{ Care-related regret coping (RCS-HCP) } \\
\hline Problem-focused & -0.03 & 0.55 & $-0.12 ; 0.06$ & -0.01 & 0.88 & $-0.14 ; 0.08$ \\
\hline Adaptive emotion-focused & 0.04 & 0.39 & $-0.05 ; 0.14$ & 0.03 & 0.61 & $-0.09 ; 0.15$ \\
\hline Maladaptive emotion-focused & -0.24 & $<0.001$ & $-0.34 ;-0.14$ & -0.15 & 0.04 & $-0.31 ;-0.03$ \\
\hline Sick leave ${ }^{\S}$ & OR & $p$ & $95 \% \mathrm{Cl}$ & OR & $p$ & $95 \% \mathrm{Cl}$ \\
\hline \multicolumn{7}{|c|}{ Most important care-related regret in the last 5 years } \\
\hline Current intensity (RIS-10) & 1.34 & 0.046 & $1.00 ; 1.78$ & 1.84 & 0.005 & $1.21 ; 2.86$ \\
\hline Self-perceived error & 1.14 & 0.71 & $0.55 ; 2.25$ & 0.97 & 0.94 & $0.39 ; 2.24$ \\
\hline \multicolumn{7}{|c|}{ Recent care-related regrets (last 30 working days) } \\
\hline Number of regrets & 1.03 & 0.82 & $0.65 ; 1.22$ & 1.04 & 0.76 & $0.57 ; 1.27$ \\
\hline Mean intensity & 1.11 & 0.46 & $0.84 ; 1.47$ & 1.05 & 0.73 & $0.77 ; 1.43$ \\
\hline \multicolumn{7}{|c|}{ Care-related regret coping (RCS-HCP) } \\
\hline Problem-focused & 0.96 & 0.77 & $0.71 ; 1.29$ & 1.01 & 0.96 & $0.71 ; 1.44$ \\
\hline Adaptive emotion-focused & 1.12 & 0.48 & $0.82 ; 1.51$ & 1.37 & 0.10 & $0.95 ; 2.00$ \\
\hline Maladaptive emotion-focused & 1.13 & 0.46 & $0.81 ; 1.54$ & 0.93 & 0.75 & $0.60 ; 1.41$ \\
\hline
\end{tabular}

* For gender, years of experience, professional status, percentage of clinical activity, and linguistic region of the hospital.

"Considered as continuous (Perneger et al., 2013): 1 = bad, 2 = fair, 3.7 = good, $4.5=$ very good, $5=$ excellent.

$\S$ In the last 6 months. This variable was dichotomized at the 75 th percentile for each profession (4 days or more for nurses and 1 day or more for physicians). 


\section{DISCUSSION}

The experience of care-related regrets - an emotional facet of moral distress - seems to be an unavoidable corollary of acute care practice, which is characterized by time pressure (Weissman et al., 2007), information overload and the increasing complexity and uncertainty related to patient care (Nevalainen et al., 2013). Moreover, suboptimal regret coping strategies may have a negative impact on clinicians' health and, eventually, on the quality of care they provide to patients (Rowe and Kidd, 2009; West et al., 2009). The aim of this study was twofold: first, to assess the cross-sectional associations between care-related regret experiences and health conditions; second, to test whether coping strategies mediated the relationships between care-related regrets and health conditions.

\section{Care-Related Regrets}

Results revealed that higher level of intensity of the most important regret in the previous 5-years was associated with poor SRH among both nurses and physicians, and with higher sick leave among nurses. In accordance with our proposed theoretical model (Courvoisier et al., 2013b), these findings suggest that lingering feelings of moral distress regarding perceived shortcomings or failures in patient care may impact healthcare professionals' own health in important ways. These findings are also in line with a recent systematic review pointing out that even if distressing experiences are not very frequent among nurses, their impact can be significant a long time after the event (Oh and Gastmans, 2015), a phenomenon which has previously been labeled "moral residue" (Webster and Baylis, 2000). In contrast, the mean intensity of recent regrets (i.e., within the previous 30 working days) was only associated with poor health among physicians. This result is in line with a socalled "crescendo effect" resulting from repetitive exposure to morally distressing situations with patients (Epstein and Hamric, 2009).

\section{Care-Related Regret Coping Strategies}

Our findings showed that maladaptive emotion-focused strategies were associated with poor SRH among nurses. This effect remained significant in the model that included all regret and socio-professional variables, in contrast to the corresponding analyses for physicians. Another difference between nurses and physicians emerged regarding the use of adaptive emotionfocused strategies: while it was positively associated both with higher SRH and lower sick leave among physicians, it was not significantly related to these variables among nurses. The positive association between adaptive regret coping strategy and physicians' health is in line with a systematic review indicating that medical errors do not only entail negative consequences, but may also result in positive outcomes related to psychological well-being and improved teamwork collaboration (Sirriyeh et al.,

TABLE 3 | Association of care-related regret with health conditions among physicians.

\begin{tabular}{|c|c|c|c|c|c|c|}
\hline \multirow[b]{2}{*}{ Self-rated health } & \multicolumn{3}{|c|}{ Adjusted analyses, regret variables not included* } & \multicolumn{3}{|c|}{ Adjusted analyses, all regret variables included* } \\
\hline & Slope & $p$ & $95 \% \mathrm{Cl}$ & Slope & $p$ & $95 \% \mathrm{Cl}$ \\
\hline \multicolumn{7}{|c|}{ Most important care-related regret in the last 5 years } \\
\hline Current intensity (RIS-10) & -0.19 & $<0.001$ & $-0.30 ;-0.08$ & -0.15 & 0.07 & $-0.32 ; 0.01$ \\
\hline Self-perceived error & 0.08 & 0.50 & $-0.14 ; 0.29$ & 0.12 & 0.34 & $-0.13 ; 0.36$ \\
\hline \multicolumn{7}{|c|}{ Recent care-related regrets (last 30 working days) } \\
\hline Number of regrets & -0.81 & 0.06 & $-1.66 ; 0.04$ & -0.11 & 0.83 & $-1.15 ; 0.93$ \\
\hline Mean intensity & -0.20 & 0.002 & $-0.32 ;-0.07$ & -0.10 & 0.18 & $-0.26 ; 0.05$ \\
\hline \multicolumn{7}{|c|}{ Care-related regret coping (RCS-HCP) } \\
\hline Problem-focused & 0.02 & 0.74 & $-0.10 ; 0.13$ & -0.07 & 0.27 & $-0.21 ; 0.06$ \\
\hline Adaptive emotion-focused & 0.17 & 0.002 & $0.06 ; 0.27$ & 0.15 & 0.02 & $0.02 ; 0.27$ \\
\hline Maladaptive emotion-focused & -0.12 & 0.01 & $-0.22 ;-0.03$ & -0.01 & 0.83 & $-0.15 ; 0.12$ \\
\hline Sick leave ${ }^{\S}$ & OR & $p$ & $95 \% \mathrm{Cl}$ & OR & $p$ & $95 \% \mathrm{Cl}$ \\
\hline \multicolumn{7}{|c|}{ Most important care-related regret in the last 5 years } \\
\hline Current intensity(RIS-10) & 0.97 & 0.83 & $0.72 ; 1.27$ & 0.75 & 0.21 & $0.48 ; 1.16$ \\
\hline Self-perceived error & 1.21 & 0.51 & $0.69 ; 2.11$ & 1.21 & 0.54 & $0.65 ; 2.25$ \\
\hline \multicolumn{7}{|c|}{ Recent care-related regrets (last 30 working days) } \\
\hline Number of regrets & 3.31 & 0.24 & $0.41 ; 24.51$ & 5.61 & 0.17 & $0.45 ; 64.7$ \\
\hline Mean intensity & 1.04 & 0.80 & $0.76 ; 1.41$ & 1.05 & 0.82 & $0.69 ; 1.55$ \\
\hline \multicolumn{7}{|c|}{ Care-related regret coping (RCS-HCP) } \\
\hline Problem-focused & 1.06 & 0.70 & $0.79 ; 1.43$ & 1.19 & 0.30 & $0.85 ; 1.68$ \\
\hline Adaptive emotion-focused & 0.76 & 0.046 & $0.57 ; 0.99$ & 0.67 & 0.01 & $0.48 ; 0.92$ \\
\hline Maladaptive emotion-focused & 1.03 & 0.81 & $0.80 ; 1.31$ & 0.97 & 0.88 & $0.67 ; 0.39$ \\
\hline
\end{tabular}

*For gender, years of experience, professional status, percentage of clinical activity, and linguistic region of the hospital.

"Considered as continuous (Perneger et al., 2013): $1=$ bad, $2=$ fair, $3.7=$ good, $4.5=$ very good, $5=$ excellent.

$\S$ In the last 6 months. This variable was dichotomized at the 75 th percentile for each profession (4 days or more for nurses and 1 day or more for physicians). 
2010). Interestingly, physicians seem better positioned than nurses to cope with negative events or unsatisfactory patient care quality, perhaps because they feel more in charge of key elements of clinical decision making. Having such efficient coping skills is susceptible to explain, at least in part, why they reported better SRH status and fewer sick leave days, when compared with nurses. An alternative explanation is that it may be more difficult for nurses to take emotional distance because they tend to have more frequent and close interactions with patients at their bedside.

Moreover, recent research suggests that coping strategies are not adaptive or maladaptive per se; rather the adaptiveness depends on the context. For instance, reappraisal may be adaptive when stressors are uncontrollable (when the person can regulate only the self) but maladaptive when stressors can be controlled (when the person can change the situation) (Troy et al., 2013). In situations when nurses have an inferior status in the hospital hierarchy, they may often renounce external problem-focused coping and instead turn to internal emotion-focused strategies, which may prove maladaptive in that they do not improve working conditions.

\section{The Meditational Role of Coping Strategies}

Irrespective of the objective incidence of difficult situations, learning how to effectively manage such situations may modulate their impact on one's health. In the clinical context, the use of adaptive and maladaptive coping strategies may help explain why similar distressing experiences occurring in patient care can entail either positive or negative consequences for healthcare professionals' own health (Courvoisier et al., 2011). Among nurses, however, there was no evidence suggesting that problemfocused and adaptive coping strategies mediated the relationship between care-related regrets and SRH.

In contrast, maladaptive coping strategies seemed to mediate the relationship between care-related regrets and SRH, suggesting that nurses' use of maladaptive strategies increases the burden associated with their most important care-related regret. This finding concurs with empirical observations that intense and frequent regrets tend to elicit the use of maladaptive strategies (Sheppes et al., 2011; Courvoisier et al., 2014).

A plausible hypothesis may well be that problem-focused and adaptive strategies are only used up to a certain level of regret; once that level is reached, people typically turn to maladaptive strategies. Nurses' perception that they lack autonomy at work may also be an additional explanatory factor (Papathanassoglou et al., 2012). In contrast, physicians' use of coping strategies mediated the effect of the number of recent healthcare-related regrets on sick leave. The use of adaptive emotion-focused coping strategies mediated the effect of the most important regret on both SRH and sick leave. To sum up, the present study provided only partial evidence for a mediating role of coping strategies, especially among nurses for whom it appears that the coping strategies exert a direct influence on their health. Programs that help healthcare professionals cope with care-related situations, like clinical supervision, debriefings and Balint groups, should be expanded for the benefit of clinicians' own wellbeing.

\section{Study Limitations}

The strengths of the current study include: (a) a relatively large sample size and recruitment in three hospitals in two different linguistic regions; (b) the use of validated scales; and (c) the inclusion of both nurses and physicians, which increases the generalizability of our results to healthcare professionals working in acute care hospitals. Nevertheless, at least three limitations have to be noted. First, our survey obtained a low response rate. Such response rates are not rare in health services research (McLeod et al., 2013), particularly on sensitive topics, such as distress, but it raises concerns about selection bias when estimating prevalence of health conditions. Despite this limitation on absolute estimates, the associations found in this study are quite congruent with the expected results (e.g., negative association of maladaptive regret coping with health). As a result, it seems rather unlikely that the associations of regret with health that we observed should differ between nonrespondents and respondents. Second, because SRH has been shown to vary by race (Landrine et al., 2016), the current results may not generalize to all races. Third, we did not adjust for some potential confounders, including night shifts, a factor that could moderate the association between regret and health. Third, due to the cross-sectional design of this study, we cannot determine the causal nature of the associations between regret and health, although the use of adjustment for socio-professional variables should limit the impact of potential confounds.

\section{CONCLUSION}

Because care-related regret is an inevitable part of clinical practice, healthcare professionals need to cope with such negative feelings. When effective, these coping skills may have the potential not only to protect healthcare professionals' own health, but also to promote better quality of care (Burston and Tuckett, 2013). Our findings suggest that physicians may be better positioned than nurses to effectively cope with negative events, notably those that were causing stronger distress. Helping healthcare professionals, especially nurses, to adopt and implement effective coping strategies in their daily practice may produce beneficial consequences at the individual, patient care, and institutional level.

\section{AUTHOR CONTRIBUTIONS}

DC and SC conceived the research idea and design. SC, BC, $\mathrm{RS}, \mathrm{TA}, \mathrm{PC}$, and DC contributed for preparing and revising the draft. SC, BC, and DC participated in the analysis of the data and were responsible for the preparation of the article. 


\section{FUNDING}

This study was supported by a grant from the Swiss National Science Foundation (SNSF) (100019_ 166010).

\section{REFERENCES}

Aasa, U., Brulin, C., Ängquist, K.-A., and Barnekow-Bergkvist, M. (2005). Work-related psychosocial factors, worry about work conditions and health complaints among female and male ambulance personnel. Scand. J. Caring Sci. 19, 251-258. doi: 10.1111/j.1471-6712.2005.00333.x

Aichele, S., Rabbitt, P., and Ghisletta, P. (2016). Think fast, feel fine, live long: a 29year study of cognition, health, and survival in middle-aged and older adults. Psychol. Sci. 27, 518-529. doi: 10.1177/0956797615626906

Arigoni, F., Bovier, P. A., and Sappino, A. P. (2010). Trend of burnout among Swiss doctors. Swiss Med. Wkly. 140:w13070. doi: 10.4414/smw.2010.13070

Bjorvatn, B., Dale, S., Hogstad-Erikstein, R., Fiske, E., Pallesen, S., and Waage, S. (2012). Self-reported sleep and health among Norwegian hospital nurses in intensive care units. Nurs. Crit. Care 17, 180-188. doi: 10.1111/j.1478-5153. 2012.00504.x

Burston, A. S., and Tuckett, A. G. (2013). Moral distress in nursing: contributing factors, outcomes and interventions. Nurs. Ethics 20, 312-324. doi: 10.1177/ 0969733012462049

Courvoisier, D. S., Agoritsas, T., Perneger, T. V., Schmidt, R. E., and Cullati, S. (2011). Regrets associated with providing healthcare: qualitative study of experiences of hospital-based physicians and nurses. PLOS ONE 6:e23138. doi: 10.1371/journal.pone.0023138

Courvoisier, D. S., Cullati, S., Haller, C. S., Schmidt, R. E., Haller, G., Agoritsas, T., et al. (2013a). Validation of a 10-item care-related regret intensity scale (RIS10) for health care professionals. Med. Care 51, 285-291. doi: 10.1097/MLR. 0b013e318280f02c

Courvoisier, D. S., Cullati, S., Ouchi, R., Schmidt, R. E., Haller, G., Chopard, P., et al. (2014). Validation of a 15-item care-related regret coping scale for healthcare professionals (RCS-HCP). J. Occup. Health 56, 430-443. doi: 10.1539/joh.140060-OA

Courvoisier, D. S., Merglen, A., and Agoritsas, T. (2013b). Experiencing regrets in clinical practice. Lancet 382, 1553-1554. doi: 10.1016/S0140-6736(13) 62325-9

DeSteno, D., Gross, J. J., and Kubzansky, L. (2013). Affective science and health: the importance of emotion and emotion regulation. Health Psychol. 32, 474-486. doi: 10.1037/a0030259

Embriaco, N., Hraiech, S., Azoulay, E., Baumstarck-Barrau, K., Forel, J. M., Kentish-Barnes, N., et al. (2012). Symptoms of depression in ICU physicians. Ann. Intensive Care 2:34. doi: 10.1186/2110-5820-2-34

Embriaco, N., Papazian, L., Kentish-Barnes, N., Pochard, F., and Azoulay, E. (2007). Burnout syndrome among critical care healthcare workers. Curr. Opin. Crit. Care 13, 482-488. doi: 10.1097/MCC.0b013e3282efd28a

Epstein, E. G., and Hamric, A. B. (2009). Moral distress, moral residue, and the crescendo effect. J. Clin. Ethics 20, 330-342.

Ghalichi, L., Pournik, O., Ghaffari, M., and Vingard, E. (2013). Sleep quality among health care workers. Arch. Iran. Med. 16, 100-103.

Glasberg, A.-L., Eriksson, S., and Norberg, A. (2008). Factors associated with 'stress of conscience' in healthcare. Scand. J. Caring Sci. 22, 249-258. doi: 10.1111/j. 1471-6712.2007.00522.x

Halford, C., Wallman, T., Welin, L., Rosengren, A., Bardel, A., Johansson, S., et al. (2012). Effects of self-rated health on sick leave, disability pension, hospital admissions and mortality. A population-based longitudinal study of nearly 15,000 observations among Swedish women and men. BMC Public Health 12:1103. doi: 10.1186/1471-2458-12-1103

Hsieh, M.-L., Li, Y.-M., Chang, E.-T., Lai, H.-L., Wang, W.-H., and Wang, S.C. (2011). Sleep disorder in Taiwanese nurses: a random sample survey. Nurs. Health Sci. 13, 468-474. doi: 10.1111/j.1442-2018.2011.00641.x

Huffman, D. M., and Rittenmeyer, L. (2012). How professional nurses working in hospital environments experience moral distress: a systematic review. Crit. Care Nurs. Clin. North Am. 24, 91-100. doi: 10.1016/j.ccell.2012.01.004

\section{SUPPLEMENTARY MATERIAL}

The Supplementary Material for this article can be found online at: http://journal.frontiersin.org/article/10.3389/fpsyg. 2017.00623/full\#supplementary-material

Hugonnet, S., Chevrolet, J.-C., and Pittet, D. (2007). The effect of workload on infection risk in critically ill patients. Crit. Care Med. 35, 76-81. doi: 10.1097/ 1001.CCM.0000251125.0000208629.0000251123F

Knecht, M., Bauer, G. F., Klaghofer, R., Buddeberg-Fischer, B., Stamm, M., and Hammig, O. (2010). Work-life conflicts and health among Swiss physicians-in comparison with other university graduates and with the general Swiss working population. Swiss Med. Wkly. 140:w13063. doi: 10.4414/smw.2010.13063

Landrine, H., Corral, I., Hall, M. B., Bess, J. J., and Efird, J. (2016). Self-rated health, objective health, and racial discrimination among African-Americans: explaining inconsistent findings and testing health pessimism. J. Health Psychol. 21, 2514-2524. doi: 10.1177/1359105315580465

Letvak, S. A., Ruhm, C. J., and Gupta, S. N. (2012). Nurses' presenteeism and its effects on self-reported quality of care and costs. Am. J. Nurs. 112, 30-38. doi: 10.1097/01.NAJ.0000411176.15696.f9

Malinauskiene, V., Leisyte, P., Romualdas, M., and Kirtiklyte, K. (2011). Associations between self-rated health and psychosocial conditions, lifestyle factors and health resources among hospital nurses in Lithuania. J. Adv. Nurs. 67, 2383-2393. doi: 10.1111/j.1365-2648.2011.05685.x

McLeod, C. C., Klabunde, C. N., Willis, G. B., and Stark, D. (2013). Health care provider surveys in the United States, 2000-2010: a review. Eval. Health Prof. 36, 106-126. doi: 10.1177/0163278712474001

Merlani, P., Verdon, M., Businger, A., Domenighetti, G., Pargger, H., and Ricou, B. (2011). Burnout in ICU caregivers: a multicenter study of factors associated to centers. Am. J. Respir. Crit. Care Med. 184, 1140-1146. doi: 10.1164/rccm. 201101-0068OC

Nevalainen, M., Kuikka, L., Sjoberg, L., Eriksson, J., and Pitkala, K. (2013). Tolerance of uncertainty and fears of making mistakes among fifth-year medical students. Fam. Med. 44, 240-246.

Oh, Y., and Gastmans, C. (2015). Moral distress experienced by nurses: a quantitative literature review. Nurs. Ethics 22, 15-31. doi: 10.1177/ 0969733013502803

Papathanassoglou, E. D., Karanikola, M. N., Kalafati, M., Giannakopoulou, M., Lemonidou, C., and Albarran, J. W. (2012). Professional autonomy, collaboration with physicians, and moral distress among European intensive care nurses. Am. J. Crit. Care 21, e41-e52. doi: 10.4037/ajcc2012205

Pauly, B., Varcoe, C., Storch, J., and Newton, L. (2009). Registered nurses' perceptions of moral distress and ethical climate. Nurs. Ethics 16, 561-573. doi: 10.1177/0969733009106649

Perneger, T. V., Gayet-Ageron, A., Courvoisier, D. S., Agoritsas, T., and Cullati, S. (2013). Self-rated health: analysis of distances and transitions between response options. Qual. Life Res. 22, 2761-2768. doi: 10.1007/s11136-013-0418-5

Perruccio, A. V., Katz, J. N., and Losina, E. (2012). Health burden in chronic disease: multimorbidity is associated with self-rated health more than medical comorbidity alone. J. Clin. Epidemiol. 65, 100-106. doi: 10.1016/j.jclinepi.2011. 04.013

Piers, R. D., Azoulay, E., Ricou, B., Ganz, F. D., Decruyenaere, J., Max, A., et al. (2011). Perceptions of appropriateness of care among European and Israeli intensive care unit nurses and physicians. JAMA 306, 2694-2703. doi: 10.1001/ jama.2011.1888

Rössler, W. (2012). Stress, burnout, and job dissatisfaction in mental health workers. Eur. Arch. Psychiatry Clin. Neurosci. 262, 65-69. doi: 10.1007/s00406012-0353-4

Rowe, L., and Kidd, M. (2009). First Do No Harm: Being a Resilient Doctor in the 21st Century. New York, NY: McGraw-Hill Medical.

Schmidt, R. E., Cullati, S., Mostofsky, E., Haller, G., Agoritsas, T., Mittleman, M. A., et al. (2015). Healthcare-related regret among nurses and physicians is associated with self-rated insomnia severity: a cross-sectional study. PLoS ONE 10:e0139770. doi: 10.1371/journal.pone.0139770

Schultz, A. B., Chen, C. Y., and Edington, D. W. (2009). The cost and impact of health conditions on presenteeism to employers: a review of the 
literature. Pharmacoeconomics 27, 365-378. doi: 10.2165/00019053-20092705000002

Seys, D., Wu, A. W., Gerven, E. V., Vleugels, A., Euwema, M., Panella, M., et al. (2013). Health care professionals as second victims after adverse events: a systematic review. Eval. Health Prof. 36, 135-162. doi: 10.1177/ 0163278712458918

Shapiro, J., Astin, J., Shapiro, S. L., Robitshek, D., and Shapiro, D. H. (2011). Coping with loss of control in the practice of medicine. Fam. Syst. Health 29, 15-28. doi: $10.1037 / \mathrm{a} 0022921$

Sheppes, G., Scheibe, S., Suri, G., and Gross, J. J. (2011). Emotionregulation choice. Psychol. Sci. 22, 1391-1396. doi: 10.1177/095679761141 8350

Singh-Manoux, A., Martikainen, P., Ferrie, J., Zins, M., Marmot, M., and Goldberg, M. (2006). What does self rated health measure? Results from the British Whitehall II and French Gazel cohort studies. J. Epidemiol. Community Health 60, 364-372. doi: 10.1136/jech.2005.039883

Sirriyeh, R., Lawton, R., Gardner, P., and Armitage, G. (2010). Coping with medical error: a systematic review of papers to assess the effects of involvement in medical errors on healthcare professionals' psychological well-being. Qual. Saf. Health Care 19, e43. doi: 10.1136/qshc.2009.035253

Thompson, C., and Dowding, D. (2001). Responding to uncertainty in nursing practice. Int. J. Nurs. Stud. 38, 609-615. doi: 10.1016/S0020-7489(00) 00103-6

Troy, A. S., Shallcross, A. J., and Mauss, I. B. (2013). A person-by-situation approach to emotion regulation cognitive reappraisal can either help or hurt, depending on the context. Psychol. Sci. 24, 2505-2514. doi: 10.1177/ 0956797613496434

Webster, G., and Baylis, F. (2000). "Moral residue," in Margin of Error: The Ethics of Mistakes in the Practice of Medicine, eds S. Rubin and L. Zoloth (Hagerstown, MD: University Publishing Group), 217-230.

Weissman, J. S., Rothschild, J. M., Bendavid, E., Sprivulis, P., Cook, E. F., Evans, R. S., et al. (2007). Hospital workload and adverse events. Med. Care 45, 448-455. doi: 10.2307/40221446

West, C. P., Tan, A. D., Habermann, T. M., Sloan, J. A., and Shanafelt, T. D. (2009). Association of resident fatigue and distress with perceived medical errors. JAMA 302, 1294-1300. doi: 10.1001/jama.2009.1389

Zeelenberg, M., and Pieters, R. (2007). A theory of regret regulation 1.0. J. Consum. Psychol. 17, 3-18. doi: 10.1207/s15327663jcp1701_3

Conflict of Interest Statement: The authors declare that the research was conducted in the absence of any commercial or financial relationships that could be construed as a potential conflict of interest.

Copyright (c) 2017 Cullati, Cheval, Schmidt, Agoritsas, Chopard and Courvoisier. This is an open-access article distributed under the terms of the Creative Commons Attribution License (CC BY). The use, distribution or reproduction in other forums is permitted, provided the original author(s) or licensor are credited and that the original publication in this journal is cited, in accordance with accepted academic practice. No use, distribution or reproduction is permitted which does not comply with these terms. 